$$
\text { Pontifícia } \operatorname{U}_{\text {Niversidade }} \text { Ce Riódólica }_{\text {de Janeiro }}
$$

Patrícia Chiganer Lilenbaum

\title{
Judeus escritos no Brasil: Samuel Rawet, Moacyr Scliar e Cíntia Moscovich
}

Tese apresentada ao Programa de Pós-graduação em Letras da PUC-Rio como requisito parcial para obtenção do título de Doutor em Letras.

Orientadora: Profa. Pina Maria Arnoldi Coco Co-orientadora: Profa. Rosana Kohl Bines 


$$
\text { Pontifícia } \operatorname{U}_{\text {Niversidade }} \text { Ce Rio délica }_{\text {danelro }}
$$

\section{Patrícia Chiganer Lilenbaum}

\section{Judeus escritos no Brasil: Samuel Rawet, Moacyr Scliar e Cíntia Moscovich}

Tese apresentada como requisito parcial para obtenção do grau de Doutor pelo Programa de Pós-Graduação em Letras da PUC-Rio. Aprovada pela Comissão Examinadora abaixo assinada.

Profa. Pina Maria Arnoldi Coco

Orientadora

Departamento de Letras - PUC-Rio

Profa. Rosana Kohl Bines

Co-orientadora

Departamento de Letras - PUC-Rio

Profa. Marília Rothier Cardoso

Departamento de Letras - PUC-Rio

Profa. Ana Paula Veiga Kiffer

Departamento de Letras - PUC-Rio

Profa. Lyslei de Souza Nascimento

UFMG

Prof. Márcio Orlando Seligmann-Silva

UNICAMP

Prof. Dr. Paulo Fernando Carneiro de Andrade Coordenador Setorial do Centro de Teologia e Ciências Humanas - PUC-Rio

Rio de Janeiro, 20 de março de 2009 
Todos os direitos reservados. É proibida a reprodução total ou parcial do trabalho sem autorização da autora, da orientadora e da universidade.

\section{Patrícia Chiganer Lilenbaum}

Possui graduação em Português-Inglês pela Universidade Federal do Rio de Janeiro (2001) e mestrado em Literatura Brasileira pela mesma instituição (2004). Lecionou no curso de graduação em Letras da Universidade Veiga de Almeida de 2003 a 2008. É, atualmente, professora do IFRJ - Campus Volta Redonda.

Ficha Catalográfica

Lilenbaum, Patrícia Chiganer

Judeus escritos no Brasil: Samuel Rawet, Moacyr Scliar e Cíntia Moscovich / Patrícia Chiganer Lilenbaum; orientadora: Pina Maria Arnoldi Coco; coorientadora: Rosana Kohl Bines. - 2009.

232 f. ; $30 \mathrm{~cm}$

Tese (Doutorado em Letras)-Pontifícia Universidade Católica do Rio de Janeiro, Rio de Janeiro, 2009.

Inclui bibliografia

1. Letras - Teses. 2. Literatura brasileira. 3. Herança. 4. Rawet, Samuel. 5. Scliar, Moacyr. 6. Moscovich , Cíntia. I. Coco, Pina Maria Arnoldi. II. Bines, Rosana Kohl. III. Pontifícia Universidade Católica do Rio de Janeiro. Departamento de Letras. IV. Título. 
Em memória de meus avós Maurice, Manha, Herschel e Chaia - traduzidos para Maurício, Maria, Henrique e Helena - de quem herdei parte do que sou. 


\section{Agradecimentos}

Agradeço imensamente às pessoas abaixo, companheiras, de diferentes formas, da minha jornada:

Pina Coco, pela generosidade da acolhida.

Rosana Kohl Bines, pelo desprendimento da generosidade. Suas orientações, críticas e elogios foram os momentos que iluminaram e possibilitaram este percurso.

Marília Rothier Cardoso, que acreditou em minhas idéias ainda seminais e se revelou uma espécie de terceira orientadora deste trabalho.

Ana Paula Kiffer, cujo curso na Pós-graduação ajudou-me a ter certeza sobre o caminho a seguir.

Israel Klabin, pela oportunidade, confiança e carinho.

Meus alunos, que me fazem refletir constantemente sobre o equilíbrio necessário entre teoria e prática.

Meus amigos, que me fazem lembrar da vida fora da escrita.

Minha família, sobretudo minha mãe, Célia, que esteve diariamente presente na vida que segue fora das linhas da tese.

Newton Júnior, par especial nesta aventura e em outras mais. 


\section{Resumo}

Lilenbaum, Patrícia; Coco, Pina Maria Arnoldi (Orientadora). Judeus escritos no Brasil: Samuel Rawet, Moacyr Scliar e Cíntia Moscovich. Rio de Janeiro, 2008. 232p. Tese de Doutorado - Departamento de Letras, Pontifícia Universidade Católica do Rio de Janeiro.

A tese investiga as relações entre a escrita e o judaísmo no contexto brasileiro, focando os autores Samuel Rawet, Moacyr Scliar e Cíntia Moscovich. A partir da imagem de escritor e da imagem de judeu que podem ser depreendidas de suas obras, busca-se traçar as diferentes possibilidades de tradução de um legado ancestral como o judaico. As vozes narrativas, nascidas da tensão entre a ficção e a autobiografia, expressam uma busca por uma identidade sempre provisória e passível de traição em diferentes graus, o que gera uma constante reflexão sobre a herança judaica e sua conexão com a palavra e com a trajetória profissional e pessoal da pesquisadora. Tal caminho dotou a tese de uma escrita autoral, que procura equilibrar a linguagem acadêmica e a pessoal.

\section{Palavras-chave}

Literatura Brasileira, Herança, Samuel Rawet, Moacyr Scliar, Cíntia Moscovich 


\section{Abstract}

Lilenbaum, Patrícia; Coco, Pina Maria Arnoldi (Advisor). Jews written in Brazil: Samuel Rawet, Moacyr Scliar and Cíntia Moscovich. Rio de Janeiro, 2008. 232p. D.Sc. Thesis - Departamento de Letras, Pontifícia Universidade Católica do Rio de Janeiro.

This thesis deals with the connections between Judaism and writing in the Brazilian context, focusing on Samuel Rawet's, Moacyr Scliar's and Cíntia Moscovich's works. Based on the image of the author and the image of the Jew that can be perceived from their works, one aims to discover different possibilities of translation of an ancestral legacy such as the Jewish one. The literary voices born out of the tension between fiction and autobiography express a search for an identity always temporary and subject to treason in different levels, which produces a constant reflection on Jewish heritage and its connection to the word and to the researcher's professional and personal path. That produceded an authoral writing which tries to balance academic and personal languages.

\section{Keywords} Moscovich

Brazilian Literature, Heritage, Samuel Rawet, Moacyr Scliar, Cíntia 


\section{Sumário}

1. O início: uma busca em espiral ou uma judia ashkenazi autofágica perdida em $\begin{array}{ll}\text { terras literárias } & 10\end{array}$

2. Glossário da busca em espiral - ou rede para o mergulho em espiral 21 Arquivo 23

Autofagia 25

Autoficção 26

Constelação 28

$\begin{array}{ll}\text { Devir } & 29\end{array}$

Escrita/Escritura $\quad 30$

Espectro $\quad 36$

Herança $\quad 38$

Identidade $\quad 39$

Judaísmo 44

Judeu imaginário $\quad 47$

Judeu não-judeu $\quad 49$

Literatura Judaica $\quad 51$

Memória $\quad 52$

Possessão $\quad 57$

Shibboleth $\quad 57$

Tradução $\quad 59$

3. Procurando caminhos 66

3.1. Os escritores e o entorno 66

3.2. Autoficção em ação: encontros reais e imaginados 69

3.3. Uma medicina e uma engenharia da escrita (e do judaísmo) 73

3.4. Pactos de escrita, pactos de leitura, pactos com o judaísmo 78

4. Samuel Rawet $\quad 81$

4.1. Uma leitura rawetiana de Samuel Rawet 81

4.2. Uma leitura não-rawetiana de Samuel Rawet 92

4.2.1. Construindo a imagem de escritor: 7 sonhos formam 1 escritor 95

4.2.2. Desconstruindo a imagem do judeu 115

5. Moacyr Scliar 129

5.1. O escritor e o judeu segundo Scliar $\quad 129$

5.1.1. A fartura, a fabulação, o humor: pacto de prazer possível 130

5.1.2. O autor que se inscreveu na tradição traída 139

5.2. O escritor e o judeu segundo as personagens sclirianas 149

5.2.1. As personagens judias (e que às vezes contam histórias) 150

5.2.2. As personagens que escrevem (e que às vezes são judias) 169

6. Cíntia Moscovich 183

6.1. Descascar e devorar cebolas 183

6.2. Riscando o fósforo...para queimar ou cozinhar 195

6.3. A mulher que se escreveu e preparou outras iguarias 199

$\begin{array}{ll}\text { 7. Considerações finais } & 214\end{array}$

8. Referências 222 
Não sou eu quem escrevo, são meus livros que me escrevem.

Clarice Lispector

A escrita transforma a coisa vista ou ouvida em força e em sangue.

Michel Foucault

Nossa herança nos foi deixada sem nenhum testamento.

René Char 